\title{
7 \\ Stealing music from/in Papua New Guinea
}

\section{Don Niles}

In contrast to the theft of intellectual, biological and most cultural properties, which occurs for the most part from Papua New Guinea, the theft of music works both ways - there are overseas thefts of Papua New Guinea music, but also Papua New Guinean thefts of overseas music. Any discussion of cultural property rights must take this into account. This chapter deliberately uses the words 'theft' and 'stealing'. In addition to being shorter and more dramatic than the phrase 'cultural property rights', it has more relevance, since it is only when people feel they have been wronged that questions of rights arise.

Traditional Papua New Guinean societies have ways of defining the rights of performance of music and dance, and also ways of dealing with transgressions. Yet because these systems seemingly function quite well, they are not a concern when it comes to the public voicing of questions about rights to performance. More of an issue is the theft of Papua New Guinean music by non-traditional groups. This generally falls into two areas - theft of traditional music by people from overseas and the theft of popular music (for example, stringband and powerband music) by other Papua New Guinean groups or overseas bands or organisations. Other thefts are possible, including the appropriation of traditional music by stringbands. Although this has not received the same level of publicity, it is certainly a concern raised by some elders when faced with the possibility of their sacred music being debased by a stringband.

Copyright concerns in Papua New Guinea have generally focused on the assumption that overseas artists are 'ripping off' local artists. While 
this has certainly happened, what is more common is the theft of overseas music by Papua New Guinean musicians. Both must be considered. The issue that has drawn the greatest attention and is the subject of most heated calls for copyright legislation is the unauthorised use of Papua New Guinean music by overseas groups, including bands, individuals and companies. The theft of Papua New Guinea music by other Papua New Guinean musicians has to be considered as well.

The use of Papua New Guinean music by overseas artists is nothing new-musicians have always sought new ideas from foreign music. In 1921, Emanuel Aarons published piano and voice arrangements of music recorded in Papua New Guinea by the Australian traveller Frank Hurley. The Australian composer Alfred Hill also made piano and voice arrangements of Papua New Guinean songs, although the results might not sound Papua New Guinean. The famous French composer Olivier Messiaen dedicated his piano composition Quatre études de rythme to the island of Papua, supposedly inspired by Papua New Guinean rhythms, and later incorporated Papua New Guinean birdsongs in one of his last orchestral works. More recently, Sr Duchesne Lavin has written many arrangements of Papua New Guinean songs, Mauricio Kagel has incorporated Papua New Guinean instruments in his compositions, Lanse Taudevin premiered his Cantata Buka in 1982 and Christopher Roberts wrote a Symphony bilong Papua. None of these compositions (see also the Annex) have raised much concern over the question of rights.

Questions about rights really only come into the spotlight when Papua New Guinean music is used-by popular musicians, in films or in other media - and the thieves have the potential to earn significant amounts of money. Papua New Guinean music has been misused in a variety of ways for differing commercial ventures. Complaints can be divided into three, occasionally overlapping categories.

\section{Use of materials without permission}

While all three categories concern lack of permission, the first category concerns the use of recordings, whether published or not, in new contexts or the commercial release of music previously not available commercially. In any case, the music is used without the permission of the collector or performer. Examples abound of such abuse within Papua New Guinea as one band complains about another band's theft of their songs, particularly after the latter has just released a cassette. Although most frequently applied to songs, theft of this kind is also reported for 
styles, for example, complaints that a certain stringband has copied the style of the Paramana Strangers or makes use of a bamboo band in an area where such ensembles are otherwise unknown.

While permission may be received for the reproduction of materials, the resulting product may be a curious mixture. For example, recordings from my own institute were used in a CD-ROM about the Maring people. However, while the colour photos and text on the CD-ROM do indeed concern the Maring, the recordings are of Enga music (Clarke 1995).

Unauthorised use also occurs in films. The Australian film To Have and To Hold uses Kaluli recordings made by anthropologist Steven Feld, apparently used without authorisation. The CD of the soundtrack lacks these examples, but does include a recording of Raun Raun Theatre, also allegedly used without permission (Raun Raun Theatre 1996: track 8), as well as recordings of Highlands flutes from an unknown source.

\section{Rerecording of a popular music song}

The rerecording of overseas popular music is a common practice in Papua New Guinea. Local groups simply record their version of a commercially released overseas hit. These are generally called 'cover versions' or simply 'covers'. Covers are an essential way of learning to make music, and sometimes the transformations of the original songs can be quite substantial, as in the wonderful reworking of Elvis's Always on My Mind by Gaba Kaluks (1985) in their song Vero.

The theft of popular Papua New Guinean songs by overseas artists is exemplified by Papua New Guinea's most well known and well publicised case of music theft-the theft of the Sanguma song Yalikoe by the Black Brothers, a band originally from Irian Jaya who resided in Papua New Guinea between 1979 and 1980. The band locally released a number of versions of Papua New Guinean pop songs, and then enjoyed a considerable success in Holland in 1982 with their version of the song (called Jalikoe), reportedly reaching third place on a European disco chart (Niles 1996). Sanguma's (1978) original version of Yalikoe is an arrangement of a traditional song from Maprik, performed by men to give them confidence and energy before going out to hunt. Sanguma's version demonstrates a conscious attempt to incorporate Papua New Guinea instruments and includes a garamut introduction. Further, there is a considerable difference between Sanguma's unaccompanied vocal section and that by the Black Brothers, which has been made without 
the use of Papua New Guinean instruments, creating a more international dance sound.

Although this was obviously straight theft by the Black Brothers without compensation to Sanguma, there does not seem to have been any discussion about what people from Maprik feel about the use of their traditional song as originally adopted by Sanguma.

\section{Manipulation of recordings}

A recording may be electronically manipulated (for example, by overdubbing or sampling) by musicians in the studio, creating a new sound. In contrast to the other two categories, this rarely occurs within Papua New Guinea. Overseas, it is an increasingly common type of music theft and Papua New Guinean music has been involved. In 1972, Pink Floyd mixed fragments of Papua New Guinean music for the sound track to a film called The Valley Obscured by Clouds (Pink Floyd 1972).

More recently, some of the Institute of Papua New Guinea Studies' own recordings have been used by a group in Germany called Miracle G(y)rlz, described on their World Wide Web home page as: 'Two guys born in Papua New Guinea with finnish [sic] parents and a drummer from Lithuania + melodic psycho-folk-punk-rock sculptures + hi-energy live-performance + intensity through 66 tracks!' (Miracle G(y)rlz nd). The Australian band Not Drowning, Waving began experimenting with their own recordings of Papua New Guinean music, eventually leading to their notable collaborations with George Telek (Not Drowning, Waving 1986, 1987, 1990a, 1990b, 1991a and 1991b). Finally, an Australian group, Drum Drum, has recently added tracks and modified recordings of Central and Manus music (Drum Drum 1996).

The most famous and commercially successful example of the manipulation of a recording of traditional music from the Pacific comes from Papua New Guinea's near neighbour, Solomon Islands. In 1969 a Swiss ethnomusicologist made recordings among the Baegu people on Malaita Island and released some of his recordings on a UNESCO disc in 1973 (Zemp 1973:track 8). Among them was a rorogwela lullaby, often sung not by the mother, but by the child's elder sister. The lyrics ask the baby not to cry because its parents are dead and no one else can hear the crying. The melody is familiar to many people as the origin of the track called Sweet Lullaby, released by Deep Forest in 1992.

In addition to being a major international hit, selling millions in the United States and Europe, and being nominated for a Grammy award, 
Deep Forest's song has been used in advertisements for Sony, Coca-Cola and Porsche. As has been well documented by the ethnomusicologist who originally recorded the work and others (Zemp 1996:44-9; Mills 1996:59-60; Feld 2000), Deep Forest (consisting of two Frenchmen) never received any permission for the use or manipulation of these recordings. No money has ever been received by UNESCO or by the ethnomusicologist who made the original recordings, and certainly no money has ever gone back to Afunakwa, the woman who sang the lullaby 23 years earlier.

\section{Responding to thefts}

These examples illustrate the types of theft that have occurred, and are likely to occur more commonly in the future, particularly as more individuals are able to make recordings and more recordings of Papua New Guinean music are available commercially. What can be done about this?

It has been suggested by many local musicians that Papua New Guinea must have a copyright law. In fact, Papua New Guinea does have a copyright law, although it is unenforceable. Reasons for this have been detailed by Nonggorr (1990; see also Niles 1992). But there are drawbacks too. If Papua New Guinea were to subscribe to international copyright legislation it would mean the end of cheap cassettes of overseas music. The price of a Michael Jackson, Abba or Don Williams cassette would probably triple, making them much too expensive for many consumers. Some may argue that such measures would benefit the local music industry, yet while there is no doubt of the popularity of some Papua New Guinean bands, would listeners be willing to abandon their favourite overseas bands in trade?

Traditional Papua New Guinean societies frequently had clear rules about ownership of music and dance and the procedures required to obtain the rights to perform it (Niles 1992). It is a feature of many groups within Papua New Guinea that they perform music that originates from outside their own area and this foreign origin is well acknowledged. This often accounts for the unintelligibility of the texts to present-day performers. Sometimes such music and dance is simply learned from neighbouring groups; perhaps more often, however, the rights to performance are purchased with traditional valuables, and the music is taught to the purchasers, ensuring that it is learnt properly. Much more is involved than just correct singing and dance movements- 
appropriate magic, taboos, decorations, rhythms and so on are essential. The buying and selling of rights to perform music seem to be particularly associated with the Mamose region, although examples could probably be found in all provinces.

Simply because there are mechanisms in place for the proper purchase of the rights of performance does not mean that thefts of music and dance do not take place. Traditional law provides ways to handle transgressions of this kind. While the Institute of Papua New Guinea Studies has received many general descriptions of such laws and the penalties associated with breaking them, to my knowledge there is nothing written in detail about how such systems operate.

Any group considering the preparation of laws for the protection of intellectual, biological and cultural rights should undertake a careful review of traditional counterparts. Unfortunately there is no detailed data of this kind, at least in the area of music. Documentation of these rules and practices is of prime importance. Perhaps in contrast to many of the other issues concerning intellectual property rights, there are traditional means of dealing with questions of ownership of music and dance. For this reason, it is important to know how these systems operate. Traditional Papua New Guinean societies have approached these issues in different ways. Knowledge will, hopefully, provide a basis for legislators to make informed suggestions about drafting laws to reflect these important precedents.

A comprehensive review of traditional intellectual property regimes will take time, but other steps can be taken now. Researchers (defined very broadly) should evaluate their own ethics when doing fieldwork in Papua New Guinea. While researchers must obviously be responsible for explaining the intended use of materials they collect, Papua New Guineans also need to be informed about these issues by someone other than researchers, so they can ask the right questions. This can be achieved by developing respect for and knowledge of the diversity of Papua New Guinean traditions, so creating a more informed populace. While people may still be eager to display their proud traditions, they need to be informed enough to enquire about possible uses of recordings or videos made of them. Politicians, as the controllers of money, need to be educated that cultural traditions are not something only to be praised at election time, but must be financially supported through the local institutions that engage in research on these traditions. The National Cultural Commission has taken important steps in recent years 
to promote Papua New Guinean cultures. It has also been exploring the use of cultural performances as a way of generating income for the practitioners themselves, thereby encouraging the maintenance of traditions.

While most researchers are very responsible, some are not. A requirement for research is that the results of research be sent back to appropriate institutions in Papua New Guinea. Some researchers fail to meet even this minimal requirement, much less return copies of their publications to the groups they have worked with. This must be monitored more closely by institutions responsible for the processing of research visas, especially the National Research Institute. Researchers must ensure that copies of every article, book, recording, film and video they produce are available in Papua New Guinea. If they do not deposit copies and cannot prove that they have done so, they should not be allowed into the country for further research until this situation is rectified.

Encouraging researchers to be ethically responsible is important, but researchers are usually not the greatest cause for concern. Rather, overseas bands looking for new sounds to sample or films needing to fill out their soundtrack with Papua New Guinean music are the most worrisome. As compact discs have become a standard medium and are relatively cheap, the sounds of music from different parts of the world have become more available than ever before. This is very exciting for any music lover, but it means that it is very easy to steal music from these kinds of recordings. Because of the huge numbers of recordings made, it is very difficult to know what has been done unless some commercial success is achieved by the thieves. Discussion needs to continue about whether Papua New Guinea should embrace international copyright conventions, given that these trends are likely to escalate in the future.

\section{Conclusion}

The importance of learning about traditional methods for the protection of cultural rights as a guide to future deliberations on this subject cannot be underestimated. It is also crucial to encourage education and awareness of what has occurred and to understand the possibilities of further occurences in the future. Making traditional music inaccessible to outsiders (local or overseas) deprives Papua New Guineans of an important symbol of their identity, yet this identity must be protected from distortion through ignorance, greed or lack of respect for these traditions. 


\section{Annex}

\section{Examples of Western compositions using Papua New Guinea} materials

Aarons, Emanuel, 1921. Pearls \& Savages; a cycle of Papuan melodies,

'Discovered' by Frank Hurley, W.H. Paling \& Co. Ltd., Sydney

[piano and voice].

Antill, John, 1958. New Guinea patrol.

Goodman, Isidore, 1944. New Guinea fantasy [for piano].

Hill, Alfred Francis, 1953. Alfred Hill's New Guinea Songs, Southern

Music Publishing Company, Sydney [piano and voice].

Kagel, Mauricio, 1971-72. Exotica [use of Papua New Guinea instruments].

Lavin, M. Duchesne, Sr., 1971. More Songs from Our Land, words by Sr.

M. Delia, Our Lady of the Sacred Heart Convent, Boroko.

_-, 1973a. Songs from Papua New Guinea Book 1, words by Sr. M.

Delia, Castle Music, St. Leonards.

—-, 1973b. Songs from Papua New Guinea Book 2, words by Sr. M. Delia, Castle Music, St. Leonards.

—-1975a. How Chaleu Became Chief; a musical play in one act for boys, based on a legend from Manus Island, words by Sr. M. Delia Donohoe. Castle Music, St. Leonards.

_- 1975b. Lotu; an English setting of the Catholic mass text, using the traditional music of Papua New Guinea (unpublished).

—, 1976a. Papua New Guinea; piano suite, J. Albert \& Son, Sydney.

_- 1976b. Singsing Tumbuna; traditional songs from Papua New Guinea, Rondor Music, Sydney.

—-1977a. Pacific Rhythm and Song: a selection from the local music of Papua New Guinea and neighbouring Pacific islands, arranged for recorders with percussion and chime bar accompaniment, Castle Music, St Leonards.

- 1977b. Theme with variations; an original PNG melody from Hus Island, Manus Island Province, Papua New Guinea, (unpublished). 
—, 1980. Sing Sing; six two part songs for Papua New Guinea, words by Sr. Delia Donahoe, Woomera Music, Reservoir, Victoria.

—, 1982. Kada Kakailai, Warner Brothers, Sydney.

—, 1990a. Missa To Rot, (unpublished).

- 1990b. Songs for a Happy Christmas, words by Sr. Dain Inglis and Sr. Delia Donahoe, Our Lady of the Sacred Heart Convent, Kensington.

—_ n.d. Malagene guvai (Come dance with us); an orchestral arrangement of selections of traditional music from Papua New Guinea (unpublished).

—, n.d. Six Papua New Guinea folk songs, (unpublished).

Messiaen, Olivier, 1949-50. Quatre études de rythme, [Dedicated to the Island of Papua], Durand, Paris.

—, 1987-91. Eclairs sur l'au-delà... [Illuminations of the Beyond...] [movement IV: White-throated gerygone (Gerygone olivacea); movement IX: New Guinea friarbird (Philemon buceroides)].

Roberts, Christopher, 1989. Symphony bilong Papua (unpublished) [for orchestra].

Sculthorpe, Peter, 1996. Simori, on Mere Bagatelles (Tall Poppies TP 080), played by Ian Munro, CD [piano pieces based on Papua New Guinea music].

Taudevin, Lansell, 1982. Cantata Buka, Lansell Taudevin, Boroko [orchestra and voices; recorded on NBC B 169]

-, 1983. Segaropa [poetry by Segg Putahu (1951-80)]. 